\title{
Die Design of Flexible Multi-Point Forming Process
}

\author{
Tahseen Fadhel Abaas * Karem MohsenYounis ** \\ Khalida kadhim Mansor *** \\ *,**,*** Department of Production Engineering and Metallurgy / University of Technology \\ *Email: tfalani@yahoo.com \\ **Email: karim_mohsen@yahoo.com \\ ***Email: kh_ak07@yahoo.com
}

(Received 30 July 2017; accepted 26 December 2017)

https://doi.org/10.22153/kej.2018.12.002

\begin{abstract}
Multi-point forming (MPF) is an advanced flexible manufacture technology, and the technology results from the idea that the whole die is separated into small punches that can be adjusted height. This idea is applied to the traditional rigid blank-holder, so flexible blank-holder $(\mathrm{FBH})$ idea can be obtained. In this work, the performance of a multi-point die is investigated with pins in square matrix and suitable blank holder. Each pin in the punch holder can be a significant moved according to the die high and at different load that applied with spring with respect to spring stiffness. The results shows the reduction in setting time with respect to traditional single point incremental forming process that lead to $(90 \%)$. and also show during the forming process, the deformation of the interpolator can induce a shape error in the formed work-piece and the blank holder can reduce/eliminate dimples that sometimes arise in the work-piece. The minimum force applied using multi-point die is $28.556 \mathrm{KN}$, while the load when complete the forming process is $30.8 \mathrm{KN}$ that caused displacement of die to $32.8 \mathrm{~mm}$.
\end{abstract}

Keywords: Flexible manufacturing, Multi-point forming, Die design, CAD and Three-dimensional surface.

\section{Introduction}

The application of sheet metal forming in aerospace, automotive, medical, and recently in renewable energy is widely used. The traditional sheet metal forming processes like the deep drawing and stamping are more adjustable to continue production, customized products, small batch and high value-added, the employment of traditional process would results long lead time, high-energy consumption, and high tooling costs. To release these limitations, the flexible sheet metal forming process concept that aimed to reduce energy consumption, incurred cost, the lead time, and has attracted significant research attentions in recent years, multi-point forming (MPF) and incremental sheet forming (ISF) are two typical flexible sheet metal forming approaches[1]. In this process method a pins matrix that arrangement approximates to continuous active surfaces of a traditional die. Each pin is vertically aligned according to the part geometry in matrix form; Figure (1) illustrated the multi-point process [2].

In this context, controlling the height of each pin is one of the main technological problems which assures the geometry of the part and avoids in general the dimpling phenomenon when Rubber multi-point forming (RMPF) without interpolator is applied. The network of small dimples affects the surface quality, mainly if such types of parts are used in automotive and aeronautical industry for exterior parts or in medicine [3].

There are many researchers who have designed die in this field but with fixed die according to the product form and there is no researcher dealing with flexible die design: 
Pham et al (2008) introduces a rapid and flexible tooling for manufacturing 3D panels using multipoint forming (MPF) methodology. MPF technology employs adjustable element matrices and each element in matrix can be controlled to adjust its coordinates for shaping a discrete 3D tooling surface [5].

B. Lu et al (2014) illustrated a developed flexible sheet metal forming concept with reduced time of forming with respect to the traditional incremental sheet metal forming process and better thickness distribution in final product. In this work, a twostep forming process has been introduced: multipoint forming as pre-forming process is applied to achieve the initial shape with the required thickness distribution. After the preforming process, used the incremental sheet metal forming process is to finalize the geometry

(a)

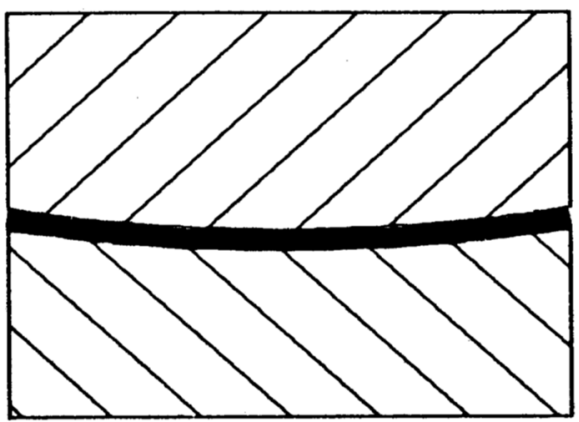

of product with the required thickness distribution [1].

Hani Aziz et al (2016) focused on simulation of multi-point die to produce the dish uses Bezier function for surface modeling to get the best modeling points for dish. The mathematical functions required to generate curves and surfaces are investigated together with complete algorithms using MATLAP program for their achievement [6].

Mohamed Abosaf et al (2017) presented the effect of process parameters, like the coefficient of friction, radius of curvature, size of pin, and elastic cushion thickness, on the formed surface quality in a flexible multipoint forming die. The aim of this research was to find the optimization of process variables used in multi-point forming process [7].

(b)

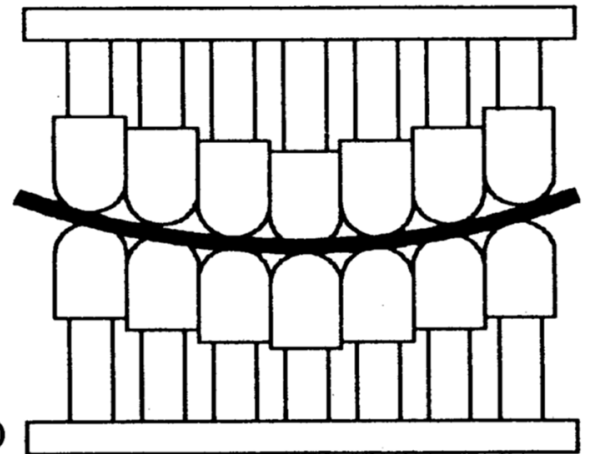

Fig. 1. comparison of multipoint forming: (a) forming die; (b) multipoint forming process. [4]

\section{Design of Multi-Point Forming Die}

The shape of multipoint forming die must be adjusting; it should be first determine the location of each punch element, then move the punch in $\mathrm{z}$ axis to form the required surface. While the $\mathrm{x}$ and $\mathrm{y}$ coordinate of all punches are stationary. Based on the tangent principle between the required surface and punch surface, the $\mathrm{z}$ coordinate of each punch can be got. Figure (2) presents the punch contact with respect to forming plate.

The function of objective surface is $f(x, y)$, the spherical radius of punch is $\left(r_{p}\right)$, the central coordinate of punch is $\left(\mathrm{x}_{\mathrm{p}}, \mathrm{y}_{\mathrm{p}}, \mathrm{z}_{\mathrm{p}}\right)$, the function of punch surface is: $[8,9]$

$\varphi= \pm \sqrt{r_{p}^{2}-\left(x-x_{p}\right)^{2}-\left(y-y_{p}\right)^{2}}+z_{p}$

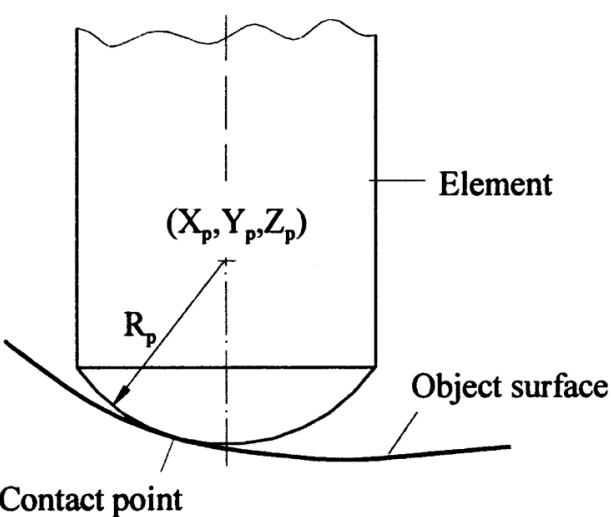

Fig. 2. Determination of element position. [8]

In this work, the developed method used to automate the adjusting of each punch with respect to fixed die surface, the punch moved by using spring mechanism, the spring mechanism control the displacement and the load applied for each punch with respect to fixed surface (die). Figure (3) presents the multi-point forming die. 

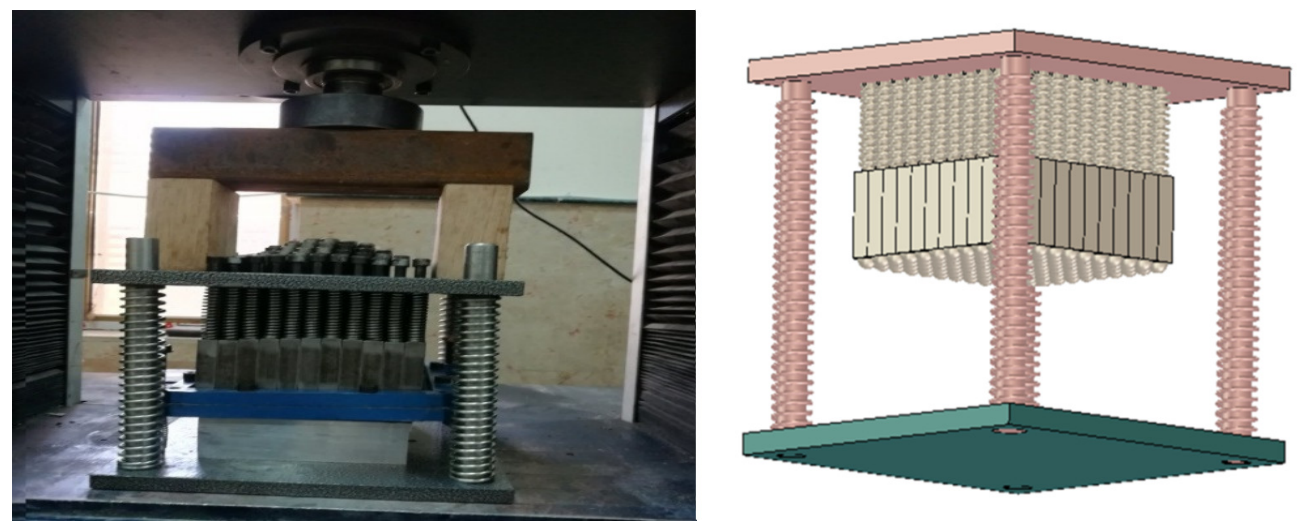

Fig. 3. multi-point forming die.

\subsection{Design calculations}

The die consists of a matrix of punch that moves inside springs that illustrated in Figure (4). Each spring when moved along (z-axis) applied the load that increase with respect to punch movement, the most important factor that effect on spring design is stiffness. And to find the

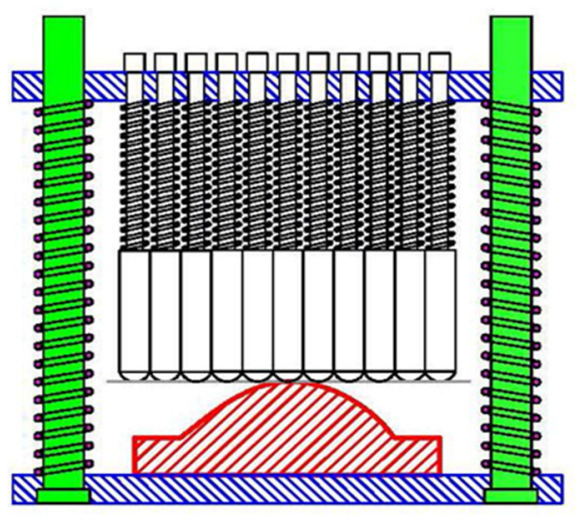

appropriate spring to applied force that cause the forming of the plate can be find as following:

$$
A=\frac{\pi}{4}(d)^{2}
$$

Where:

A: the maximum contact area between spherical punch and forming plate

d:maximum diameter that contact the forming plate (=Diameter of punch/2).

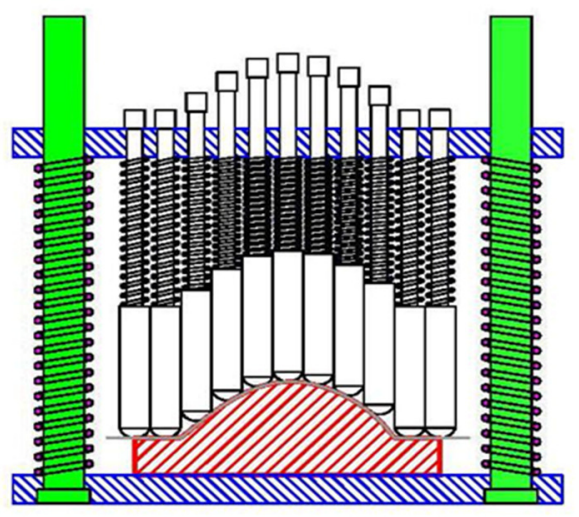

Fig. 4. Schematic the multi-point forming die (without load, and after applying the load when finishing forming process).

In this work, the diameter of punch is selected $(\mathrm{D}=15 \mathrm{~mm})$, the maximum diameter contact to the forming plate equal to the radius of the punch at the edge of the die as illustrated in Figure (5). So, using equation (2) to find the area of punch: $A=\frac{\pi}{4}(15 / 2)^{2}=44.156 \mathrm{~mm}^{2}$

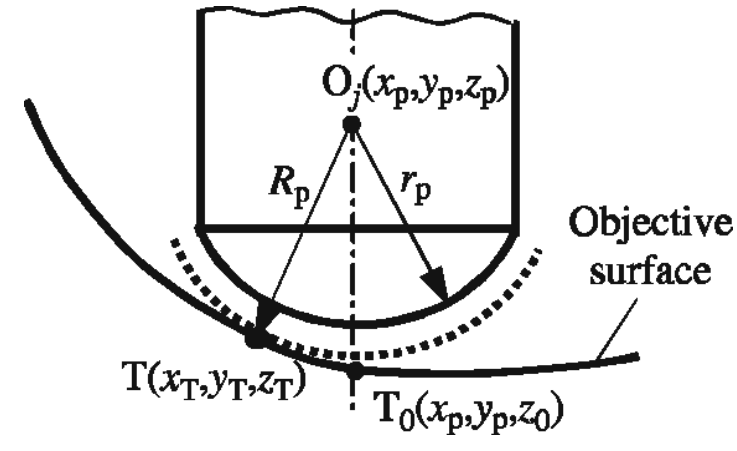

Fig. 5. The maximum contact area between the bunch and the forming plate. 
And to find the maximum force and displacement that applied on forming punch using the compression test result of selected spring was illustrated in Figure (6).

From load-deformation curve above, the maximum load applied in spring is (236 $\mathrm{N})$ (y-axis) caused maximum displacement (44mm) (x-axis).

$\sigma=\frac{F}{A}=\frac{236}{44.156}=5.344 \mathrm{~N} / \mathrm{mm}^{2}$

$F=K * \delta$

$K=\frac{F}{\delta}=\frac{236}{44}=5.36 \mathrm{~N} / \mathrm{mm}$

Where:

F: maximum force applied on spring
K: Spring Stiffness

$\delta$ : Maximum displacement of spring

And when using the matrix of punch $(11 * 11=121$ punch), the maximum force applied to forming the plate is:

$\mathrm{F}=236 * 121=28556 \mathrm{~N}=28.556 \mathrm{KN}$

Through the value of the spring stiffness was calculated, the kind of spring can be chosen in which the metal could be formed, As well as through the calculations it is clear that the minimum force that can be applied using the current forming die design is $28.556 \mathrm{KN}$, with addition to friction force between springs and guides that not exiting to $10 \%$.

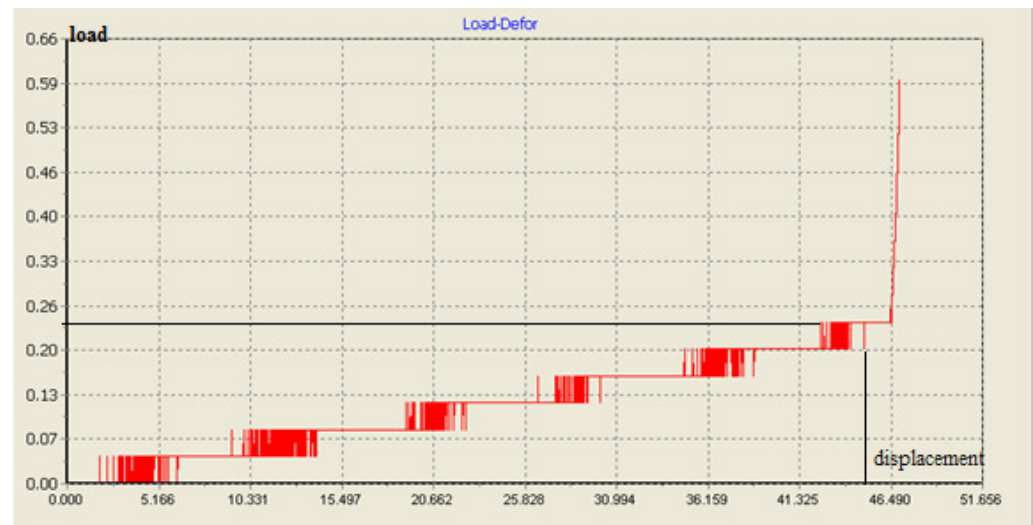

Fig. 6. load-Deformation Test Result.

\section{Design Process}

The experimental work can be descripting briefly in the following steps:

4.1 Design the square punch shape $(15 \mathrm{~mm})$ and $(77.5 \mathrm{~mm})$ in length with spherical forming end with radius $(7.5 \mathrm{~mm})$, With an internal tooth diameter of $8 \mathrm{~mm}$ and depth of $40 \mathrm{~mm}$. The process of manufacturing was done on a turning machine and with four jaw chuck and the manufacture of a curving mold with a $(9.5 \mathrm{~mm})$ radius of arc as shown in Figure (7).

4.2 Design the spring that applied the force with (80mm length and $13 \mathrm{~mm}$ diameter). Spring type is selected as indicated by its calculations above.
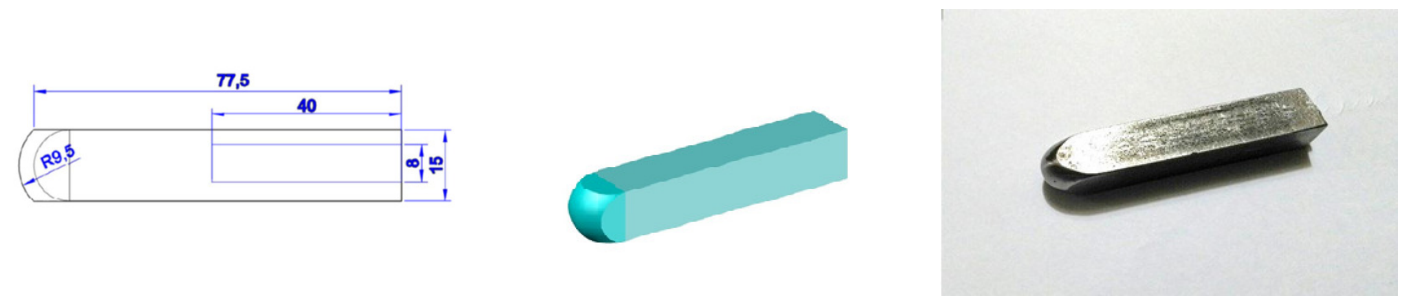

Fig. 7. Dimension of punch that used in this work.

4.3Design and manufacturing the upper plate for die with matrix $\left(11^{*} 11\right)$ with $(0.1 \mathrm{~mm})$ clearance using $\mathrm{CNC}$ milling machine that illustrated in Figure (8-A), this plate used to fixed the punches as shown in Figure (8-B).
4.4 Design and manufacturing the lower plate and guides with (diameter $=26 \mathrm{~mm}$ and length $260 \mathrm{~mm}$ ) as shown in Figure (8-C\&D).

4.5 Manufacturing the punches and its guides. 4.6 Assembly the final die. 
4.7 Manufacturing the part that need to forming using Bezier surface and machine in $\mathrm{CNC}$ milling machine.

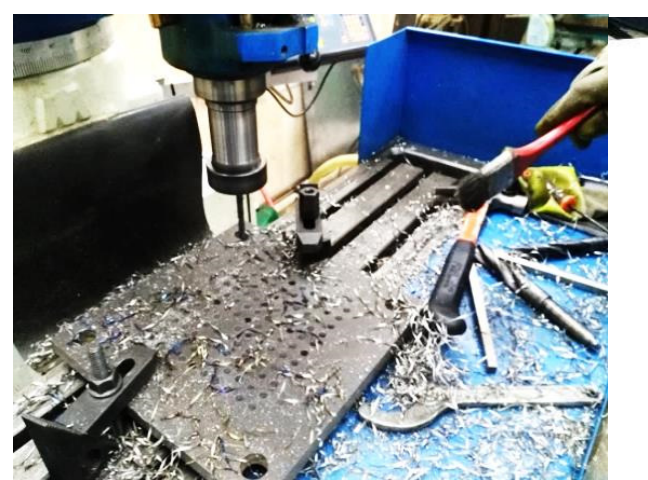

(A)

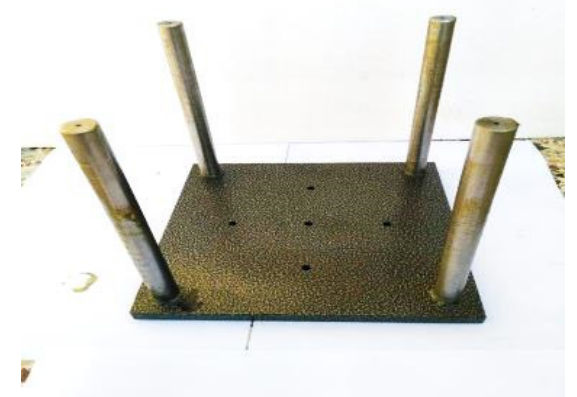

(C)
4.8 Forming the plate using the developed die that illustrated in Figure (9).

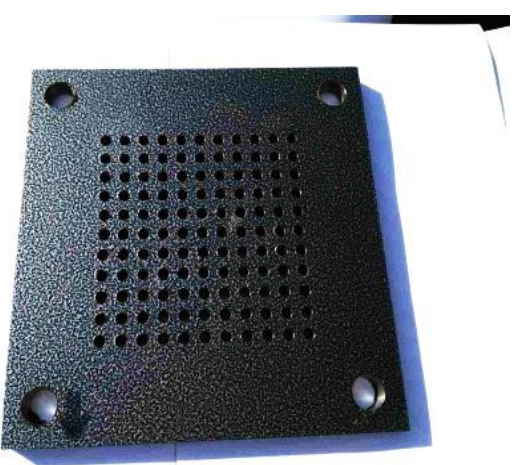

(B)

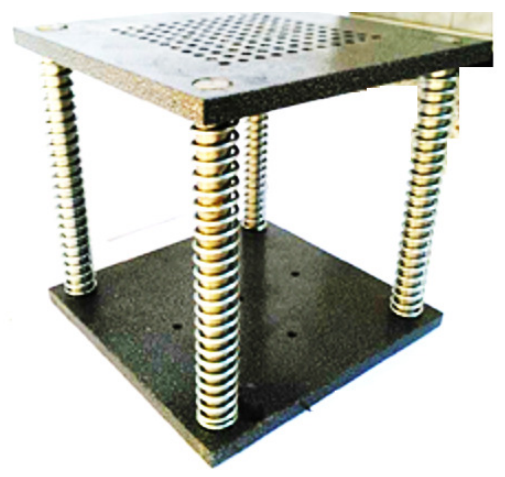

(D)

Fig. 8. Stages of die manufacturing, (A,B) upper plate, (C) lower plate and guides and (D) forming die after assembly upper plate, lower plate and guides.

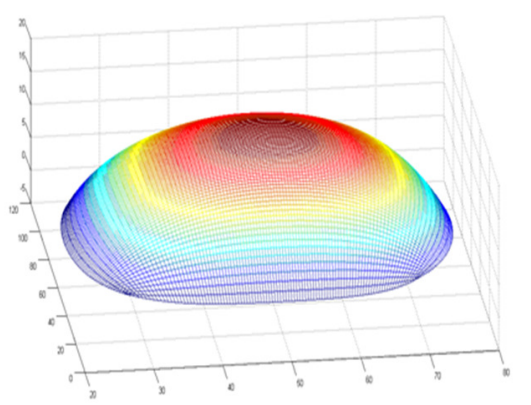

(A)

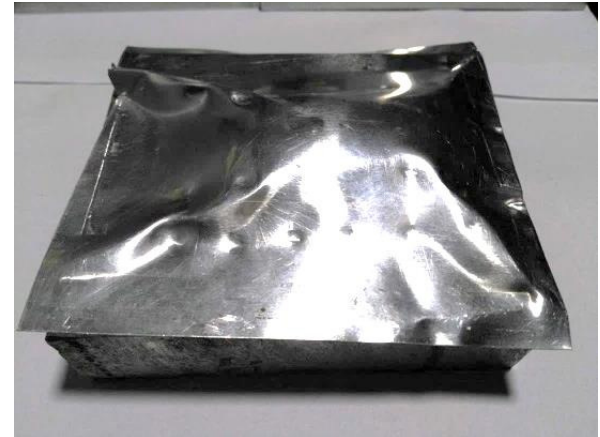

(C)

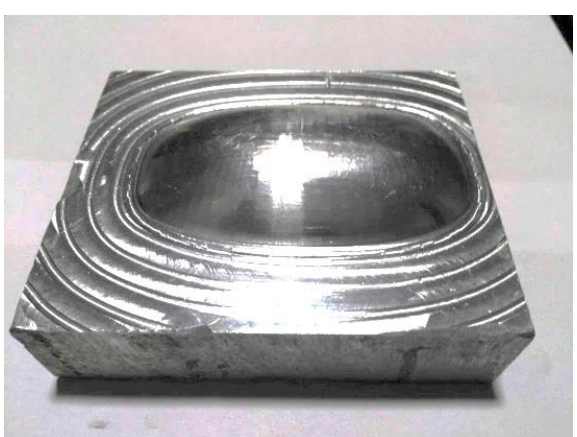

(B)

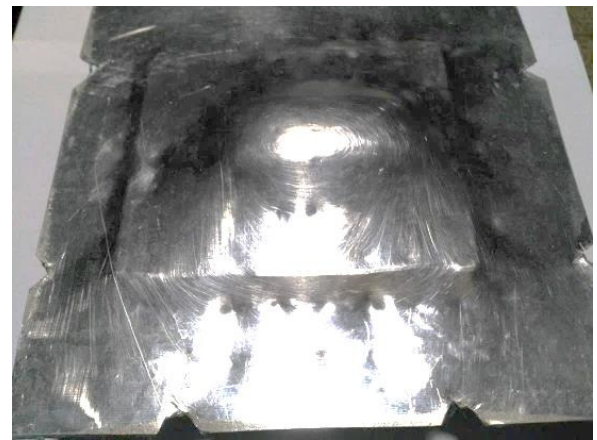

(D)

Fig. 9. CAD-design and the product manufacturing using multi-point forming die (A) CAD-design (B) forming die (C) final product without blank holder (D) final product using blank holder. 


\section{Results and Discussion}

In multi-point forming process, the load is gradually increased smoothly to $14.45 \mathrm{KN}$, which corresponds to $8.25 \mathrm{~mm}$ of the upper die displacement. At this point, all pins were in contact to the forming plate and plastic deformation started to take place. After that, the force rapidly increased with plastic deformation due to strain hardening of the material [7]. The maximum force that taken from chart of (loaddeform) is about $30.8 \mathrm{kN}$ when the upper and lower dies are closed at forming depth $32.8 \mathrm{~mm}$;
Figure (10) presented the forming load and displacement in this process. the advantage of this method is lower forming time with respect to incremental forming process, because the forming time depending on the speed of load applied, in this work, the speed used is $10 \mathrm{~mm} / \mathrm{min}$ and by moving to maximum displacement $(32.8 \mathrm{~mm})$ the total time required to complete this process is $3.2 \mathrm{~min}$, while the average forming time required to forming this shape using incremental forming process is (2035 ) min depending on feed rate [10]. So the reduction of process time exists to $90 \%$.

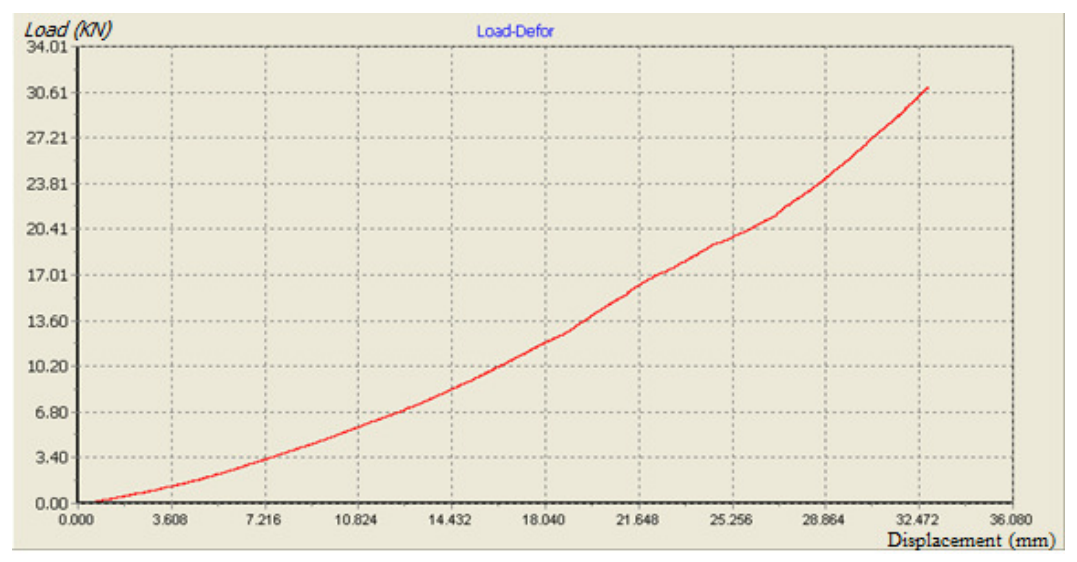

Fig. 10. Forming load-displacement chart result in multi-point forming process.

\section{Conclusions}

This work proposed a new design of multipoint forming die to control the displacement and force that applied on each punch to increase the flexibility of forming process and reduce adjusting time required for each product, this study demonstrated the following:

1. Multi-point sheet metal forming is good method for flexible forming but have the limitation one of them is adjusting time and dimension accuracy that required a high skill technical to achieve this sitting.

2. Using the sliding punch that control of the displacement and load applied from each punch on forming product give a good result with reduce of setting time more than $90 \%$.

3. Blank holder in multi-point process is very important to reduce the wrinkling in the final product and distribute the force on the blank.
4. One of the limitations of this process is a dimple on final product that must be treatment.

\section{References}

[1] B. Lu, H. Zhang, D.K. Xu and J. Chen, A Hybrid Flexible Sheet Forming Approach Towards Uniform Thickness Distribution, International Conference on Manufacture of Lightweight Components - ManuLight2014.

[2] Viorel Paunoiu and Virgil Teodor, Geometric reconfiguration of the multipoint forming dies using reverse engineering, the annals of "DUNĂREA DE JOS" university of Galati fascicle, technologies in machine building ISSN 1221- 4566, 2009.

[3] A A Tolipov, A Elghawail, M Abosaf, S Shushing, D Pham and K Essa, Experimental research and numerical optimisation of multipoint sheet metal forming implementation using a solid elastic cushion system, School of Engineering, University of Birmingham, Conference Paper · July 2017 
[4] Mingzhe Li, Yuhong Liu, Shizong Su, Guandgquan Li, Multi-point forming: a flexible manufacturing method for a 3-d surface sheet, Jilin University of Technology, Changchun 130025, People's Republic of China.1997

[5] D.T. Pham, S.Z. Su1, M.Z. Li , C.G. Liu, F. Carrai, F. Massabe, A.M.Yan and M. Vinay, FLXIBLE TOOLING FOR MANUFACTURING 3D PANELS USING MULTI-POINT FORMING METHODLOGY, Manufacturing Engineering Centre, Cardiff University, Cardiff, United Kingdom, Conference Paper June 2008

[6] Hani Aziz Ameen, Haidar Akram Alsabti and Zahraa Abdul Kareem Radhi, Finite Element Analysis of the Dish Multi-Point Forming Process , International Journal of Engineering Research \& Technology (IJERT), Vol. 5 Issue 07, July-2016.
[7] Mohamed Abosaf, Khamis Essa, Ali Alghawail, Abror Tolipov, Shizhong Su and Duc Pham, Optimisation of multi-point forming process parameters, Int J Adv Manuf Technol, 2017.

[8] Heli Peng, Mingzhe Li, Chunguo Liu and Junhui Cao, Study of multi-point forming for polycarbonate sheet, Int $\mathrm{J}$ Adv Manuf Technol, 67:2811-2817, 2013.

[9] Se Yun Hwang, Jang Hyun Lee, Yong Sik Yang and Mi Ji Yoo, Springback adjustment for multi-point forming of thick plates in shipbuilding, Elsevier journal, ComputerAided Design 42, 1001-1012, 2010.

[10] Q. Mohamed Doss, Tahseen Fadhel Abaas and Aqeel Sabree Bedan, The effect of tool path strategy on twist behavior in Single Point Incremental Sheet Metal Forming, Journal of Engineering, Baghdad University, Vol. 4, 2013. 


\title{
تصميم وتنفيذ قالب مرن لعملية التثكيل المتعدد النقاط
}

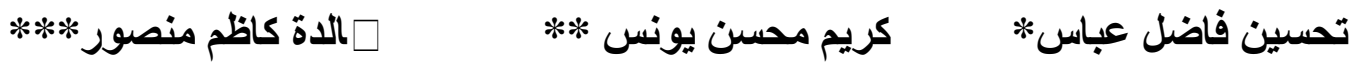

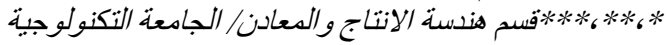

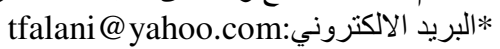

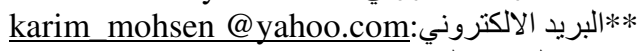

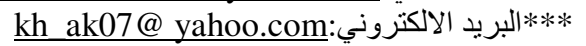

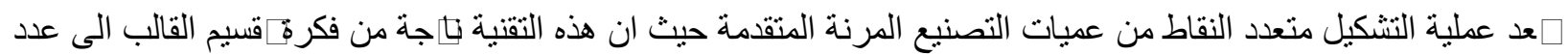

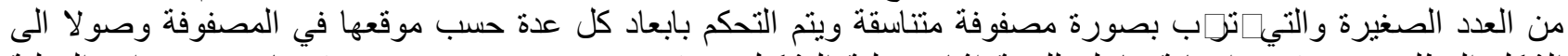

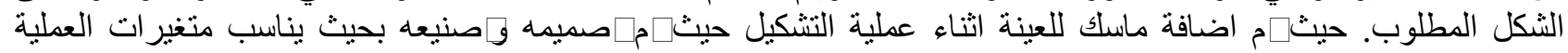

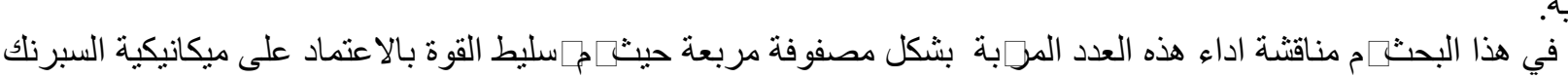

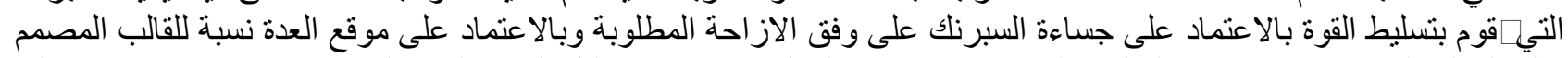

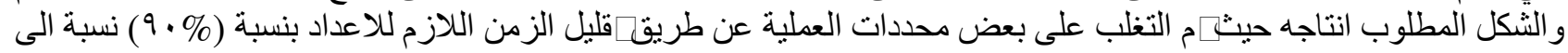

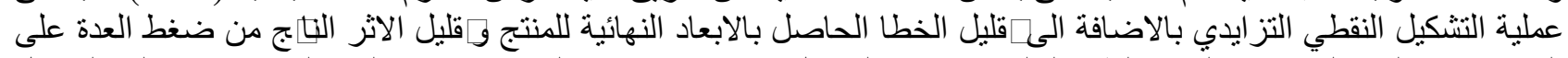

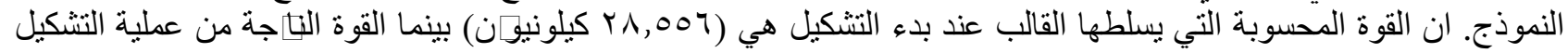

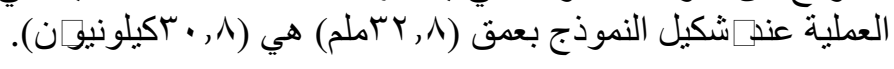

